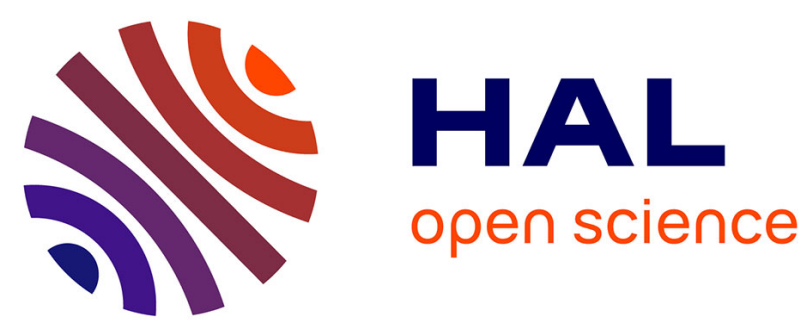

\title{
Potential and limitations of on-line comprehensive reversed phase liquid chromatographyxsupercritical fluid chromatography for the separation of neutral compounds: An approach to separate an aqueous extract of bio-oil
}

Morgan Sarrut, Amélie Corgier, Gérard Crétier, Agnès Le Masle, Stéphane Dubant, Sabine Heinisch

\section{- To cite this version:}

Morgan Sarrut, Amélie Corgier, Gérard Crétier, Agnès Le Masle, Stéphane Dubant, et al.. Potential and limitations of on-line comprehensive reversed phase liquid chromatographyxsupercritical fluid chromatography for the separation of neutral compounds: An approach to separate an aqueous extract of bio-oil. Journal of Chromatography A, 2015, 1402, pp.124-133. 10.1016/j.chroma.2015.05.005 . hal-01176925

\author{
HAL Id: hal-01176925 \\ https://hal.science/hal-01176925
}

Submitted on 30 Sep 2015

HAL is a multi-disciplinary open access archive for the deposit and dissemination of scientific research documents, whether they are published or not. The documents may come from teaching and research institutions in France or abroad, or from public or private research centers.
L'archive ouverte pluridisciplinaire HAL, est destinée au dépôt et à la diffusion de documents scientifiques de niveau recherche, publiés ou non, émanant des établissements d'enseignement et de recherche français ou étrangers, des laboratoires publics ou privés. 
1 Potential and Limitations of On-line Comprehensive Reversed Phase Liquid 2 Chromatography $\mathrm{x}$ Supercritical Fluid Chromatography for the Separation of

3 Neutral Compounds: An approach to Separate Aqueous Extract of Bio-oil.

4

Morgan Sarrut ${ }^{1}$, Amélie Corgier ${ }^{1}$, Gérard Crétier $^{1}$, Agnès Le Masle ${ }^{2}$, Stéphane Dubant $^{3}$, Sabine Heinisch ${ }^{1 *}$

\author{
${ }^{1}$ Université de Lyon, Institut des Sciences Analytiques, UMR CNRS UCBL ENS 5280, 5 rue de la \\ Doua, 69100 Villeurbanne, France \\ ${ }^{2}$ IFP Energies nouvelles, Rond-Point de l'échangeur de Solaize, BP3, 69360 Solaize, France \\ ${ }^{3}$ Waters SAS, BP608, 78056 St Quentin en Yvelines, France \\ *Corresponding author - Tel : +33(0)437 423551 ; E-mail address : sabine.heinisch@univ-lyon1.fr
}

\title{
Abstract
}

On-line comprehensive Reversed Phase Liquid Chromatography $x$ Supercritical Fluid Chromatography (RPLC x SFC) was investigated for the separation of complex samples of neutral compounds. The presented approach aimed at overcoming the constraints involved by such a coupling. The search for suitable conditions (stationary phases, injection solvent, injection volume, design of interface) are discussed with a view of ensuring a good transfer of the compounds between both dimensions, thereby allowing high effective peak capacity in the second dimension. Instrumental aspects that are of prime importance in on-line 2D separations, were also tackled (dwell volume, extra column volume and detection). After extensive preliminary studies, an on-line RPLCXSFC separation of a bio-oil aqueous extract was carried out and compared to an on-line RPLCXRPLC separation of the same sample in terms of orthogonality, peak capacity and sensitivity. Both separations were achieved in 100 min. For this sample and in these optimized conditions, it is shown that RPLCxSFC can generate a slight higher peak capacity than RPLCxRPLC (620 vs 560). Such a result is essentially due to the high degree of orthogonality between RPLC and SFC 
which may compensate for lesser peak efficiency with SFC as second dimension. Finally, in the light of the current limitations of SFC instrumentation for on-line 2D analyses, RPLCxSFC appears to be a promising alternative to RPLCxRPLC for the separation of complex samples of neutral compounds.

\section{Keywords}

Supercritical fluid chromatography (SFC); RPLC x SFC; Comprehensive twodimensional chromatography; Biomass by-products

\section{Introduction}

Over the last decades, on-line comprehensive two-dimensional liquid chromatography (LCXLC) has grown significantly in many application fields [1-4]. Liquid chromatography provides a wide variety of separation modes including Reversed Phase Liquid Chromatography (RPLC), Normal Phase Liquid Chromatography (NPLC), Steric Exclusion Chromatography (SEC), Ion Exchange Chromatography (IEC) and Hydrophilic Interaction Liquid Chromatography (HILIC). On-line coupling two of these different techniques via an appropriate interface may produce a separation system capable of generating a very high effective peak capacity in a reasonable analysis time while avoiding sample loss and/or sample contamination [5].

To maximize the potential of a two-dimensional system, one of the key problems is to find orthogonal conditions between the two dimensions in order to obtain a separation that uses the largest possible fraction $(\mathrm{Y})$ of the separation space [6]. In this regard, NPLCXRPLC was shown to be very attractive for the separation of pharmaceutical compounds [7]. However, in spite of a lower degree of orthogonality, RPLCXRPLC has often been preferred to avoid peak deterioration associated with the incompatibility of the mobile phase of first dimension with that of second dimension (stronger eluting power or immiscibility) $[2,8,9]$ and finally to obtain an interesting sample peak capacity for the overall comprehensive system. 
Bio-oil samples are mainly composed of small neutral compounds. Two very recent papers $[10,11]$ presented successful separation of aqueous bio-oil extracts by on-line RPLCXRPLC with a retention space coverage close to $50 \%$ only. NPLCXRPLC could be a possible solution to increase the utilized portion of the available space. In this work, we experiment another option which consists in coupling RPLC to supercritical fluid chromatography (RPLCxSFC). This approach was expected to be attractive because of the variety of mechanisms that govern retention in these two chromatographic systems [12]. West and Lesellier showed that polar stationary phases in SFC tend to behave as in NPLC [13]. Little polar stationary phases were also found to be attractive with SFC mobile phases as recently reported in a study which compared their use in SFC and RPLC [14]. On-line SFCxRPLC was investigated by François et al. [15] for the separation of fatty acids in fish oils and compared to on-line RPLCXRPLC for the separation of the same sample. $92 \%$ of the separation space was occupied in SFCxRPLC versus $55 \%$ in RPLCxRPLC. However, SFCxRPLC arrangement needed a particular interface composed of two two-position/ten-port switching valves equipped with two loops packed with octadecyl silica allowing both the depressurization of the supercritical fluid and the trapping and focusing of the analytes after an addition of water to the first dimension eluent and before the transfer to the second dimension. The potential of RPLCxSFC was highlighted by Stevenson et al. [16] in off-line mode. On-line RPLCxSFC has never been investigated yet. Here we describe our development of on-line RPLCxSFC for the separation of aromatic neutral compounds and an aqueous extract of bio-oil. With a liquid eluent in the first dimension, the interface between the two dimensions is simpler than that used in SFCXRPLC and similar to that used in RPLCXRPLC. Moreover, in the second dimension, the low viscosity of SFC mobile phase allows very fast analysis, which is of prime importance to increase peak capacity in on-line two-dimensional separations. This paper deals with the choice of SFC stationary phase, the study of phenomena resulting from the injection of a polar sample solvent into a supercritical mobile phase and the experimental and instrumental aspects related to the interface. Finally, a comparison between RPLCxSFC and RPLCxRPLC separations of the same aqueous bio-oil extract is proposed in terms of orthogonality, effective peak capacity and sensitivity. 


\section{Experimental}

\subsection{Material and reagents}

Acetonitrile (ACN) (HPLC grade), methanol (MeOH) and acetone were purchased of HPLC grade from Sigma-Aldrich (Steinheim, Germany). Water was obtained from an Elga water purification system (Veolia water STI, Le Plessis Robinson, France). Pressurized liquid CO2 3.0 grade (99.9\%) was obtained from Air Liquide (Pierre Bénite, France).

The synthetic sample for RPLCxSFC experiments was chosen among different compounds known to be representative of those found in bio-oil aqueous samples [10]. It contains a-hydroxycumene, phenol, 2,4,6-trimethylphenol, 1-indanone, syringol, angelica lactone, m-cresol, o-cresol, anisole, guaiacol, 5-methylfurfural and phenylethanol. They were dissolved in water/ACN 85/15 v/v at the concentration of 50 $\mathrm{mg} / \mathrm{L}$. Physical properties of these twelve compounds are reported in Table 1. The compounds were either obtained from Sigma-Aldrich or graciously given by IFP Energies nouvelles (Solaize, France). The bio-oil aqueous sample was provided by IFP Energies nouvelles.

\subsection{Columns}

Four columns $(50 \times 2.1 \mathrm{~mm}, 1.7 \mu \mathrm{m})$ from Waters (Milford, MA, USA) were used under SFC conditions : Acquity UPC ${ }^{2}$ BEH-2EP, Acquity UPC ${ }^{2} \mathrm{BEH}$, Acquity UPC $\mathrm{CSH}^{2}$ Fluoro-Phenyl and Acquity UPC ${ }^{2}$ HSS C18. Three columns were used under RPLC conditions : XBridge C18 (50x1.0 mm $3.5 \mu \mathrm{m})$ from Waters, Hypercarb $(100 \times 1 \mathrm{~mm}, 5$ $\mu \mathrm{m})$ from Thermo Scientific (Cheshire, UK) and Acquity CSH Phenyl-Hexyl (50x2.1 $\mathrm{mm}, 1.7 \mu \mathrm{m})$ from Waters.

\subsection{Apparatus}

\section{D-SFC system}


124 Waters Acquity UPC ${ }^{2}$ system was equipped with a binary solvent delivery pump, a 250 $\mu \mathrm{L}$ mixing chamber, an autosampler with a $10 \mu \mathrm{L}$ loop, two column ovens compatible with temperature up to $90^{\circ} \mathrm{C}$ and including two 6-channel column selection valves, a UV detector with a $8 \mu \mathrm{L}$ flow-cell and a backpressure regulator (BPR). The allowed maximum flow rate is $4 \mathrm{~mL} / \mathrm{min}$. The allowed maximum pressure is 410 bar for flowrates up to $3.25 \mathrm{~mL} / \mathrm{min}$. This limit pressure linearly decreases to 290 bar when the flow rate increases to $4 \mathrm{~mL} / \mathrm{min}$. Data acquisition was performed by Empower software (Waters). The extra-column volume and extra-column variance were measured under liquid chromatographic conditions. They were equal to $83 \mu \mathrm{L}$ and $132 \mu \mathrm{L}^{2}$ respectively. The system dwell volume was estimated at $300 \mu \mathrm{L}$ (see section 2.4.1.).

RPLCXRPLC system

The RPLCXRPLC system was a 2D-IClass liquid chromatograph from Waters. This instrument includes two high-pressure binary solvent delivery pumps, an autosampler with a flow-through needle of $15 \mu \mathrm{L}$, a column manager composed of two column ovens with an allowed maximum temperature of $90^{\circ} \mathrm{C}$ and two 6-port high pressure twoposition valves acting as interface between the two separation dimensions, a UV detector and a diode array detector equipped with $500 \mathrm{~nL}$ flow-cells. For the first dimension, the allowed maximum pressure is 1280 bar for flow-rates up to $1 \mathrm{~mL} / \mathrm{min}$; it linearly decreases to 850 bar when flow rate increases to $2 \mathrm{~mL} / \mathrm{min}$. For the second dimension, the maximum pressure is 1280 bar for flow-rates up to $1.4 \mathrm{~mL} / \mathrm{min}$; this limit linearly decreases to 1170 bar when flow rate increases to $2 \mathrm{~mL} / \mathrm{min}$. The measured dwell volume was $110 \mu \mathrm{L}$ and $120 \mu \mathrm{L}$ for the first and second dimensions respectively. A total extra-column volume of $12 \mu \mathrm{L}$ and $17 \mu \mathrm{L}$ and an extra-column variance of $4 \mu \mathrm{L}^{2}$ and $9 \mu \mathrm{L}^{2}$ were determined for the first and the second dimension respectively.

To ensure a fair comparison between RPLCxRPLC and RPLCxSFC experiments, the original interface made of two 6-port valves was replaced by a 10-port high pressure 2-position valve (Vici Valco Instruments, Houston, USA) equipped with two identical loops of $20 \mu \mathrm{L}$. Data acquisition, the instrumental control of the two dimensions and the programming of the 10-port high pressure 2-position valve interface were performed by Masslynx software (Waters). 
158 The first dimension consisted in the high-pressure binary solvent delivery pump, the column manager and the diode array detector of the 2D-IClass apparatus. The second dimension consisted in the high-pressure binary solvent delivery pump, the UV detector and the BPR of the Acquity UPC² apparatus, set at 140 bar. As in RPLCXRPLC, the 10-port high pressure 2-position valve was used as interface between the two dimensions. It was equipped with two identical loops of 3 or $5 \mu \mathrm{L}$. A $30 \mathrm{~cm} \times 175 \mu \mathrm{m}$ i.d. tubing was used between the mixer of SFC pump and the 10-port 2-position valve. A $56 \mathrm{~cm} \times 175 \mu \mathrm{m}$ i.d. tubing was connected between the valve and the $31.8 \mathrm{~cm} \times 175 \mu \mathrm{m}$ i.d. preheater of the second dimension column. Finally, the UV detector was connected to the column outlet by $30 \mathrm{~cm} \times 175 \mu \mathrm{m}$ i.d. tubing. Instrumental characteristics were determined for the SFC second dimension : $300 \mu \mathrm{L}$ for the dwell volume, , $57 \mu \mathrm{l}$ for the extra-column volume and $50 \mu \mathrm{L}^{2}$ for the extra-column variance. The RPLCxSFC setup is presented in Figure 1.

Both instrument control for the first dimension and interface programming were performed by Masslynx software. Data acquisition and instrument control for the second dimension were performed by Empower software dedicated to Acquity UPC ${ }^{2}$ instrument. Synchronization between both dimensions was obtained by connecting electrically the two systems and by using external events in the first dimension method

\subsection{Chromatographic procedures}

In LC the dwell volume, $V_{D}$, is usually determined from a gradient experiment performed without column using $\mathrm{MeOH}$ as solvent $\mathrm{A}$ and $\mathrm{MeOH}+0.1 \%$ acetone as solvent $\mathrm{B}$. The gradient is programmed on a wide range of composition, typically from 1 to $99 \% B$, in order to minimize the uncertainty on $V_{D}$ value. This latter is obtained by multiplying the measured dwell time, to, by the flow rate used to perform the gradient experiment. $t_{D}$ is calculated from the time, $t^{*}$, corresponding to the half-part of the UV signal between the start and the end of the gradient $\left(t_{D}=t^{*}-t_{G} / 2\right.$, $t_{G}$ being the gradient time). For $V_{D}$ determination, SFC mobile phases are composed with $\mathrm{CO}_{2}$ as solvent $\mathrm{A}$ and $\mathrm{MeOH}+0.1 \%$ acetone as solvent $\mathrm{B}$. It was found that when the initial composition of the programmed gradient was rich in $\mathrm{CO}_{2}$ (e.g. $\left.1 \% \mathrm{~B}\right)$, the obtained 
191 gradient profile was not perfectly linear, which led to a high uncertainty $\Delta \mathrm{t}$ on the 192 gradient middle time $t^{*}$ and consequently on the dwell volume $V_{D}$ (Fig. 2a). From the experiment shown in Fig.2a, VD was in fact estimated at $600 \pm 300 \mu \mathrm{L}$. This abnormal behavior is likely to be due to the supercritical nature of the mobile phase at high percentages of $\mathrm{CO}_{2}$.In order to correctly assess $V_{D}$ in SFC, the gradient was therefore started with a higher percentage of $\mathrm{MeOH}+0.1 \%$ acetone (i.e. $69 \% \mathrm{~B}$ ) in order to get a quasi-liquid phase since the beginning of the gradient. Under these conditions the observed gradient profile was actually linear as shown in Fig. 2 b and thus, the dwell volume measurement was much more reliable (i.e. $300 \pm 40 \mu \mathrm{L}$ ).

The compatibility of the four SFC stationary phases (Acquity UPC ${ }^{2}$ HSS C18, Acquity UPC $^{2}$ CSH FP, Acquity UPC ${ }^{2}$ BEH and Acquity UPC ${ }^{2}$ BEH-2EP) with LC injection solvents composed of different water/ACN proportions was tested in isocratic conditions, namely 95/2.5/2.5 $\mathrm{CO}_{2} / \mathrm{MeOH} / \mathrm{CAN}$. The temperature, the flow rate, the $\mathrm{BPR}$, the wavelength and the sampling rate were set at $45^{\circ} \mathrm{C}, 2.7 \mathrm{~mL} / \mathrm{min}, 140 \mathrm{bar}$, $215 \mathrm{~nm}$ (compensation from 350 to $450 \mathrm{~nm}$ ) and $40 \mathrm{~Hz}$ respectively for all the experiments. The effect of injection solvent composition on the peak shape of o-cresol was only studied with the Acquity UPC ${ }^{2} \mathrm{BEH}-2 \mathrm{EP}$ column. The flow rate was set at 2.2 $\mathrm{mL} / \mathrm{min}$. Other conditions were those mentioned above.

\section{RPLCXSFC}

RPLCxSFC experiments related to the effect of RPLC solvent injection on pressure increase in second dimension were performed with the following conditions. In first dimension, X-Bridge BEH C18 column was used with mobile phase consisted in Water (A) and $\mathrm{ACN}(\mathrm{B})$; the gradient profile was : $0 \mathrm{~min}, 1 \% \mathrm{~B} ; 29.3 \mathrm{~min}, 55 \% \mathrm{~B} ; 31.05 \mathrm{~min}$, $1 \%$ B; 55 min, $1 \%$ B; the flow rate was $10 \mu \mathrm{L} / \mathrm{min}$. In second dimension Acquity UPC ${ }^{2}$ $\mathrm{CSH}$ FP and Acquity UPC ${ }^{2} \mathrm{BEH}$ were used at $2.0 \mathrm{~mL} / \mathrm{min}$ and $2.6 \mathrm{~mL} / \mathrm{min}$ respectively

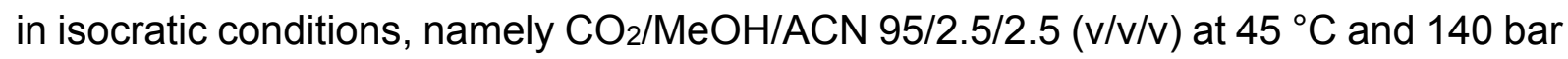
as BPR. The sampling time was $0.3 \mathrm{~min}$. The loop volume of the interface was $3 \mu \mathrm{L}$.

The conditions of the RPLCXSFC separation of both synthetic sample and aqueous bio-oil extract are given in Tables 2 and 3 respectively.

221 The conditions of the RPLCxRPLC separation of aqueous bio-oil extract are given in 222 Table 3. 


\section{Calculations}

The experimental sample peak capacities were calculated according to

$226{ }^{j} n=\frac{t_{n}-t_{1}}{w}$

$227 t_{n}$ and $t_{1}$ are the retention times of the most and the least retained compound respectively and $w$ is the average $4 \sigma$ peak width (13.4\% of peak height). Exponent $j$ stands for the dimension number.

231 Effective sample peak capacities were calculated by the following relationship [10]:

$n_{2 D, \text { effective }}=\alpha \cdot{ }^{1} n \cdot(1-\gamma)+\gamma \cdot\left(\alpha \cdot{ }^{1} n \cdot{ }^{2} n\right)$

$233 \gamma$ is the correction factor corresponding to the ratio of the practical to the theoretical

234 retention area. Its calculation is detailed in reference [6]. $\alpha$ is the undersampling rate

235 introduced by Davis et al. [17] :

$236 \alpha=\frac{1}{\sqrt{1+0.21(6 / \tau)^{2}}}$

237 where $\tau$ is the sampling rate of the 2D-separation (i.e. the number of fractions sent to

$238{ }^{2} \mathrm{D}$ per $6 \sigma$ peak width in $\left.{ }^{1} \mathrm{D}\right)$.

239

240 2D-data were processed using calculation tools developed under Excel 2007 and

241 Matlab V7.12.0635.

\section{Results and discussion}

\subsection{Theoretical considerations}

246 The peak capacity in the second dimension ${ }^{2} \mathrm{n}$ increases with the ratio of the gradient

247 time to the column dead time, ${ }^{2} \mathrm{t}_{\mathrm{G}} /{ }^{2} \mathrm{t}_{0}$. It is important to note that the increase in ${ }^{2} \mathrm{n}$ can 248 be significant in the range of low ${ }^{2} \mathrm{t}_{\mathrm{G}} / 2 \mathrm{t}_{0}$ values which are usually considered in the 
second dimension. It is therefore of prime importance to do everything possible to enhance this ratio. As previously discussed [4], this ratio can be expressed by

$\frac{{ }^{2} t_{G}}{{ }^{2} t_{0}}=\frac{t_{s}}{{ }^{2} t_{0}}-\left[\frac{{ }^{2} V_{D}}{{ }^{2} V_{0}}+(1+x)\right]$

where $t_{s}$ is the sampling time, ${ }^{2} V_{D}$ is the ${ }^{2} \mathrm{D}$ dwell volume, ${ }^{2} V_{0}$ is the ${ }^{2} \mathrm{D}$ column dead volume and $x$ is the number of column volume required for ${ }^{2} \mathrm{D}$ column equilibration between two gradient runs.

Eq. (4) highlights the need for (i) low ${ }^{2} t_{0}$ and therefore the use of a short ${ }^{2} \mathrm{D}$ column providing high efficiency i.e. packed with sub $2 \mu \mathrm{m}$ particles and/or the use of a high linear velocity as that usually required under SFC conditions, (ii) low ${ }^{2} V_{D} /{ }^{2} V_{0}$ which is not favorable for SFC as second dimension because a rather large dwell volume is present in the current SFC instrumentation, (iii) few column volumes to equilibrate the ${ }^{2} D$ column (i.e. low $x$ value) and (iv) a substantial sampling time $t_{s}$. However $t_{s}$ affects the injection volume in ${ }^{2} \mathrm{D},{ }^{2} \mathrm{~V}_{\mathrm{i}}$, according to

${ }^{2} V=t_{s} \times{ }^{1} F$

Where ${ }^{1} \mathrm{~F}$ is the flow-rate in ${ }^{1} \mathrm{D}$.

Critical injection effects have been reported under SFC conditions, especially when using polar injection solvents and/or large injection volumes [18,19]. With RPLC as first dimension, the injection solvent in ${ }^{2} \mathrm{D}$ is composed of water and an organic solvent, typically ACN. To the best of our knowledge, no study has been devoted to hydroorganic mixtures as injection solvents in SFC. Thus, the two following sections present a thorough study to determine the maximum injection volume depending on both mobile phase composition in ${ }^{1} \mathrm{D}$ and stationary phase in ${ }^{2} \mathrm{D}$.

In order to minimize ${ }^{2} \mathrm{~V}_{i}$ and since flow-splitting is impossible between the first RPLC dimension and the second SFC dimension to avoid $\mathrm{CO} 2$ depressurization when the valve is switched, ${ }^{1} \mathrm{~F}$ was set at the lowest value $(10 \mu \mathrm{L} / \mathrm{min})$ recommended in gradient elution for the UHPLC instrument. As a result a $1 \mathrm{~mm}$ i.d. column was found to be the most appropriate column geometry for the first dimension.

\subsection{Effect of injection of a large water volume on inlet pressure increase}


In SFC, when the injection solvent contains water, we observed a pressure increase (denoted $\Delta \mathrm{P}$ ) which occurs a few seconds after the injection process. Then, the pressure slowly decreases to its initial value. This phenomenon is shown in Fig.3a for 1D-SFC conditions and in Fig. $3 b$ for a ${ }^{2} D$ run in RPLC $x$ SFC conditions. The injection process is different between these two configurations. In 1D-SFC, the sample is pressurized before injection thanks to a particular design of the UPC ${ }^{2}$ injection system. This pressurization step results in an immediate sharp pressure increase followed by a sharp decrease down to the working pressure. In RPLC x SFC the injection system of the UPC ${ }^{2}$ instrument is not used. The sample is sent from the ${ }^{1} \mathrm{D}$ RPLC column to the sample loop and then injected in the SFC ${ }^{2} \mathrm{D}$ column when the 10 -port valve is switched. As a result, the preceding sharp increase does not occur. However, in both cases, the same pressure increase $\Delta \mathrm{P}$ can be observed. We have measured $\Delta \mathrm{P}$ under different conditions in 1D-SFC. The experiments were focused on the behavior of 4 different SFC stationary phases subjected to 3 different injection volumes $(1,5$ and 10 $\mu \mathrm{L})$ with 3 different injection solvents differing in their water content $(95 \%, 50 \%$ and $5 \%$ ). Among the four studied stationary phases, two were fairly apolar (Acquity CSH FP and Acquity HSS C18) while two were significantly polar (Acquity BEH and Acquity BEH-2EP). The obtained results, given in Fig.4, clearly show that $\Delta \mathrm{P}$ increases both with the injection volume and with the percentage of water in the injection solvent. It is also very interesting to note that the pressure increase is markedly higher with less polar stationary phases (Figs. $4 a$ and $4 b$ ) resulting in an inlet pressure exceeding the pressure limit authorized by the instrument for $10 \mu \mathrm{L}$ injected in $95 \%$ water. In this situation, $\Delta \mathrm{P}$ was much higher than $80 \mathrm{bar}$ while it remained lower than $40 \mathrm{bar}$ for the two polar stationary phases (Figs. $4 \mathrm{c}$ and $4 \mathrm{~d}$ ). For $5 \mu \mathrm{L}$ injected, $\Delta \mathrm{P}$ is still high on less polar stationary phases compared to polar stationary phases ( 50 vs 5 bar at $95 \%$ water and 10 vs 2 bar at $50 \%$ water).

306 The problem of pressure increase was found to be much more critical during a RPLC x SFC separation as highlighted in Fig.5.The inlet pressure of the ${ }^{2} \mathrm{D}$ SFC instrument was recorded when an Acquity CSH FP column (Fig.5a) and an Acquity BEH column were used in ${ }^{2} \mathrm{D}$ (Fig.5b). SFC conditions were strictly identical for both columns, except flow rate set at $2.0 \mathrm{~mL} / \mathrm{min}$ and $2.6 \mathrm{~mL} / \mathrm{min}$ for Acquity CSH FP and Acquity $\mathrm{BEH}$ respectively. The sampling time was $0.3 \mathrm{~min}$. Consequently $3 \mu \mathrm{L}$ of liquid solvent were injected in the ${ }^{2} \mathrm{D}$ SFC column every $0.3 \mathrm{~min}$. The composition of this liquid 
313 injection solvent changes gradually as the gradient in the ${ }^{1} \mathrm{D}$ column progresses. This 314 variation is easily assessed by means of the ${ }^{1} \mathrm{D}$ gradient profiles given in Figs. 5a and 315 5b. With an apolar stationary phase (Fig.5a), whereas the inlet pressure at the time of 316 injection was 315 bar, it reached 400 bar after 10 runs. This pressure that is very close 317 to the instrument pressure limit was kept nearly constant during 20 minutes before 318 slowly decreasing down to the initial inlet pressure when the percentage of water 319 becomes lower than $70 \%$. This phenomenon was not observed with polar stationary 320 phases (Fig.5b). To explain this, we suggest that, unlike polar stationary phases, apolar 321 ones are poorly wetted by injection solvents rich in water, which finally results in local change of mobile phase nature. Due to the short analysis time in the second SFC dimension ( $0.3 \mathrm{~min}$ ), these successive modifications have no time to be swept away. They eventually accumulate to form a multiphase plug (composed of $\mathrm{CO}_{2}$, water, $\mathrm{MeOH}$ and $\mathrm{ACN}$ ) which is more viscous than the original monophasic mobile phase ( $\mathrm{CO}_{2}-\mathrm{MeOH}-\mathrm{ACN}$ mixture).

In addition to this critical problem of pressure increase with apolar stationary phases which prevents from working in at high flow-rates in ${ }^{2} \mathrm{D}$, significant baseline fluctuations are observed for the fractions that are separated during the pressure plate (Fig.2c). Conversely no baseline fluctuation is noted for fractions that are analyzed when the inlet pressure is back to normal (Fig.5e). With ${ }^{2} \mathrm{D}$ polar stationary phases the ${ }^{2} \mathrm{D}$ inlet pressure remains constant during the whole RPLC x SFC separation (Fig.5b) and no disruption of the baseline is visible whatever the considered fractions (Figs. $5 d$ and $5 f$ ).

In the light of these results, it is clear that a polar stationary phase should be preferably used for the SFC second dimension. Re-injection of very low injection volumes $(<1 \mu \mathrm{L})$ in ${ }^{2} \mathrm{D}$ could probably circumvent the problems encountered with apolar stationary phase but it should lead to quite unrealistic sampling time $(<0.1 \mathrm{~min})$. Another alternative would be to start the RPLC gradient with a water content lower than $70 \%$. However this option is not possible for compounds that are poorly retained in RPLC such as small polar compounds. Considering the above results, Acquity BEH-2EP was chosen as ${ }^{2}$ D SFC stationary phase for the rest of this study. 1D-SFC 
in SFC, it was recently shown [19] that the injection solvent composition strongly influences peak shapes. Very polar solvents such as DMSO and $\mathrm{MeOH}$ were found to lead to significant peak distortions even for low injected volumes, these distortions being more pronounced for less retained compounds. Abrahamsson et al. [18] also studied the effect of various injection solvents in accordance with the stationary phase. They pointed out that injection solvent may interact with stationary phase, mobile phase and solute, thereby affecting either positively or negatively peak shape. However the effect of water as injection solvent on peak shape has never been studied neither as pure solvent, probably due to the fact that it is highly polar and not much miscible with $\mathrm{CO}_{2}$, nor combined with other solvents. Here, we have studied the impact of injected volume on peak shape when the solute is dissolved in different water/ACN mixtures. Results obtained with CO2/ACN/MEOH 95/2.5/2.5 (v/v/v) as SFC mobile phase and o-cresol as solute are shown in Fig.6. Surprisingly, when the injected volume does not exceed $5 \mu \mathrm{L}$ (i.e. $5 \%$ of the column dead volume), a very high content of $\mathrm{ACN}$ in injection solvent seems to be more damaging for the peak shape than a high content of water (Figs.6a and 6b). It is possible to inject up to $5 \mu \mathrm{L}$ of sample dissolved in a solvent containing 50 to $95 \%$ water without strong peak distortion. Obviously, for $10 \mu \mathrm{L}$ injected (Fig.6c) which represents $10 \%$ of the column dead volume, the peak shapes are very bad for all studied injection solvents. The results shown in Fig.6 also point out the retention shift that increases with both the percentage of water in the injection solvent and the injection volume. It is likely to be due to two combined effects: (i) good affinity of water for the polar sites of the stationary phase and (ii) high affinity of o-cresol for water. Consequently, when the injection plug enters the column, o-cresol interacts preferentially with the stationary phase thereby increasing retention. Such retention shift could be damaging for 2D-chromatogram reconstruction due to difficulty in peak assignment between consecutive fractions analysis. However, this problem does not really arise in RPLC x SFC since the injection solvent composition slightly varies between the 2 to 4 consecutive ${ }^{2} \mathrm{D}$ runs that are required in comprehensive twodimensional chromatography to minimize undersampling [17]. In view of this study, it was decided to inject a maximum of $5 \mu \mathrm{L}$ in the second SFC dimension. Since flow splitting between ${ }^{1} D$ and ${ }^{2} D$ was not possible with a LCxSFC configuration, injection volume in ${ }^{2} \mathrm{D}$ was directly related to both ${ }^{1} \mathrm{D}$ flow-rate and sampling time. Accordingly, with $10 \mu \mathrm{L} / \mathrm{min}$ as ${ }^{1} \mathrm{D}$ flow-rate, the sampling time could not be higher than 30 s. 
In order to validate the choices made previously to carry out the on-line RPLCxSFC experiments, 12 aromatic compounds were separated. The experimental conditions are given in Table 2. The sampling time and the ${ }^{1} \mathrm{D}$ flow rate being equal to $0.5 \mathrm{~min}$ and $10 \mu \mathrm{L} / \mathrm{min}$ respectively, two identical sample loops of $5 \mu \mathrm{L}$ were installed on the 10 -port switching valve in order to completely fill the sample loop. This configuration avoids dissolving issues as highlighted in Fig.7. When the sample loop is in inject position, it is filled with the SFC mobile phase. When the sample loop comes back in load position it is depressurized, allowing some droplets of organic modifier covering the walls of the loop. Whereas this droplets can be well solubilized in the RPLC mobile phase coming from ${ }^{1} \mathrm{D}$ (Fig.7a) they may cause troublesome issues with the SFC mobile phase if the sample loop is partially filled (Fig.7b). In addition the presence of air to push the sample plug can be detrimental compared to the SFC mobile phase which is better dissolved in the hydro-organic liquid solvent. The obtained RPLCxSFC separation is presented in Fig.8a. It is interesting to notice the large occupation of the retention space by the 12 compounds, underlining the great interest of this coupling in terms of orthogonality. Furthermore, as highlighted in Fig.8b showing the separation of four consecutive fractions, peak shapes are quite symmetrical as could be expected from our preliminary studies. With 0.83 s as average $4 \sigma$ peak width the sample peak capacity is close to 15 in the second dimension.

4.5 Comparison of RPLC $\times$ RPLC and RPLC $\times$ SFC systems for the separation of a bio-oil sample

An RPLCXSFC experiment was carried out on a real sample consisting in an aqueous extract of a bio-oil. The conditions of the first dimension were similar to those used in a previous study [10] except the gradient time that is much lower in the present work. In order to elute all the compounds in ${ }^{2}$ D SFC conditions, a gradient from $15 \%$ to $50 \%$ $\mathrm{MeOH} / \mathrm{ACN}(1: 1)$ is needed. The contour plot of the RPLCxSFC separation is presented in Fig.9a. For comparison, Fig.9b shows the RPLCxRPLC separation of the same sample performed using the same ${ }^{1} \mathrm{D}$ conditions as the RPLCXSFC separation. 
412 For a better comparison of the two separations, the sampling time was also kept 413 identical (i.e. 30s). As a consequence, ${ }^{1} \mathrm{n}$ and $\alpha$ were identical for both separations.

414 Experimental conditions are given in Table 3.

415 Fig. 9 clearly underlines that the RPLCXSFC system offers much higher degree of 416 orthogonality ( $\gamma$ close to 1 ) compared to the RPLCxRPLC configuration ( $\gamma$ close to 0.6). 417 It is important to note that this latter configuration and the corresponding conditions 418 displayed in Table 3 were found to provide the highest effective peak capacity among 419 the different studied RPLCxRPLC systems [10]. In RPLCxSFC, the enhancement of 420 the available separation space allows to reach an effective peak capacity slightly 421 higher in spite of a higher ${ }^{2} n$ with RPLCxRPLC conditions (see Table 4). Several 422 reasons could explain why ${ }^{2} \mathrm{n}$ is higher with RPLC as second dimension: (i) ${ }^{2} \mathrm{t}_{\mathrm{G}} /{ }^{2} \mathrm{t}_{0}$ ratio was more than three times higher for RPLCxRPLC (5.4 vs 1.7 for RPLCXSFC) leading to a higher peak capacity in second dimension according to eq. (4) and as discussed in section 4.1. Indeed, despite $a^{2} t_{s} /{ }^{2} t_{0}$ ratio in favor of RPLCxSFC due to the higher flow rate used in SFC $(2.0 \mathrm{~mL} / \mathrm{min}$ vs $1.2 \mathrm{~mL} / \mathrm{min}$ in RPLC), the dwell volume is larger in SFC (300 $\mu \mathrm{L}$ vs $120 \mu \mathrm{L}$ in LC) increasing ${ }^{2} \mathrm{~V}_{\mathrm{D}}{ }^{2} \mathrm{~V}_{0}$ ratio. Moreover, for software reasons, an extra-time of $0.2 \mathrm{~min}$ had to be added between two consecutive runs of second dimension in SFC, thereby leading to a real acquisition time of only $0.3 \mathrm{~min}$. As a consequence, while the number of column volumes used for column equilibration, $x$, was set at 2 for RPLC as second dimension, $x$ was equal to 4 for SFC, which therefore significantly decreased ${ }^{2} \mathrm{t}_{\mathrm{G}} /{ }^{2} \mathrm{t}_{0}$ ratio. It was shown that only two column dead volumes $(x=2)$ can provide a good run-to-run repeatability in UHPLC conditions [20-22] which was also found to be suitable for SFC conditions for neutral compounds (data not shown).

(ii) The extra-column variance is markedly higher with SFC apparatus compared to UHPLC apparatus and led to an important loss of efficiency especially for $50 \times 2.1 \mathrm{~mm}$ column [23]. In our case the extra-column variance in 2D was 3.5 times larger in RPLCxSFC (32 $\mu \mathrm{L}^{2}$ vs $9 \mu \mathrm{L}^{2}$ in RPLCxRPLC). This is mainly due to both larger tubing i.d. and larger flow-cell volume of the UV detector used in SFC $(175 \mu \mathrm{m}$ and $16 \mu \mathrm{L}$ respectively) compared to those used in RPLC (65 $\mu \mathrm{m}$ and $0.5 \mu \mathrm{L}$ respectively). (iii) Some significant injection effects still exist in RPLCxSFC whereas none were observed in RPLCXRPLC. The compatibility of the mobile phases of the two dimensions is more challenging in RPLCXSFC which may involve more critical injection effects. Moreover, while all the peaks in the ${ }^{2} \mathrm{D}$ RPLC have nearly the same width (i.e. 
$4460.6 s$ ), the peak shapes obtained in ${ }^{2} \mathrm{D}$ SFC were not similar with $\mathrm{w}_{4 \sigma}$ varying from 0.51

$447 \mathrm{~s}$ to $1.50 \mathrm{~s}$ depending on the compounds. As a result the average measured peak width 448 at $4 \sigma$ was $0.60 \mathrm{~s}$ in RPLC compared to $1.09 \mathrm{~s}$ in SFC conditions. More pronounced 449 injection effects, resulting in a loss of column efficiency, could also probably explain 450 the 7 -fold loss in sensitivity when using SFC as second dimension compared to RPLC 451 making RPLCXSFC less attractive in terms of sensitivity.

452 Finally, despite the raised instrumental issues, the present results show that 453 RPLCXSFC can be a good alternative to RPLCXRPLC for the separation of biomass by-products

\section{Conclusions}

The goal of this work was to evaluate the potential of on-line RPLCXSFC for the separation of aromatic compounds. Suitable stationary phase and injection volume for the ${ }^{2} \mathrm{D}$ SFC were chosen thanks to preliminary studies aiming at overpassing the lack of compatibility between the mobile phases used as first and second dimension. Polar stationary phases in SFC seem to be the most adapted stationary phases. On the other hand it was shown that a maximum of $5 \mu \mathrm{L}$ of a mixture of water/acetonitrile was appropriate to inject in the second SFC dimension. An on-line RPLCxSFC separation of a real aqueous bio-oil sample was successfully carried out achieving full orthogonality $(\gamma=1)$, while with an optimized RPLCXRPLC separation $\gamma$ could not exceed 0.59. Accordingly, although wider peaks were observed in SFC as second dimension, the effective peak capacity was slightly higher with RPLCxSFC configuration (620 vs 560 with RPLCxRPLC). However, it should be noted that the peak capacity in ${ }^{2}$ D SFC was limited by the high dwell volume of the apparatus as well as software issues due to this unusual coupling. Consequently, we are sure that there is still room for further improvements. Yet, sensitivity was found markedly higher with the RPLCXRPLC separation due to an important extra-column variance with the SFC system and still pronounced injection effects in SFC. Finally, in the light of these results, on-lineRPLCxSFC can be considered as an interesting alternative for the separation of neutral compounds compared to RPLCxRPLC.

\section{Acknowledgements}


M.S., S.H. and G.C. wish to thank Waters for the loan of the UPC ${ }^{2}$ system and especially Philippe Mériglier for his help in LCxSFC setting up. S.H. would like to thank Davy Guillarme for stimulating discussions and valuable advice on different aspects of SFC.

[1] P. Dugo, F. Cacciola, T. Kumm, G. Dugo, L. Mondello, J. Chromatogr. A 1184 (2008) 353.

[2] I. François, K. Sandra, P. Sandra, Anal. Chim. Acta 641 (2009) 14.

[3] P.Q. Tranchida, P. Donato, F. Cacciola, M. Beccaria, P. Dugo, L. Mondello, TrAC Trends Anal. Chem. 52 (2013) 186.

[4] M. Sarrut, G. Crétier, S. Heinisch, TrAC Trends Anal. Chem. 63 (2014) 104.

[5] G. Guiochon, N. Marchetti, K. Mriziq, R.A. Shalliker, J. Chromatogr. A 1189 (2008) 109.

[6] A. D’Attoma, C. Grivel, S. Heinisch, J. Chromatogr. A 1262 (2012) 148.

[7] I. François, A. De Villiers, P. Sandra, J. Sep. Sci. 29 (2006) 492.

[8] K.J. Mayfield, R.A. Shalliker, H.J. Catchpoole, A.P. Sweeney, V. Wong, G. Guiochon, J. Chromatogr. A 1080 (2005) 124.

[9] P. Jandera, J. Sep. Sci. 29 (2006) 1763.

[10] A. Le Masle, D. Angot, C. Gouin, A. D'Attoma, J. Ponthus, A. Quignard, S. Heinisch, J. Chromatogr. A 1340 (2014) 90.

[11] D. Tomasini, F. Cacciola, F. Rigano, D. Sciarrone, P. Donato, M. Beccaria, E.B. Caramão, P. Dugo, L. Mondello, Anal. Chem. 86 (2014) 11255.

[12] G. Guiochon, A. Tarafder, J. Chromatogr. A 1218 (2011) 1037.

[13] C. West, E. Lesellier, J. Chromatogr. A 1110 (2006) 191.

[14] A. Grand-Guillaume Perrenoud, J.-L. Veuthey, D. Guillarme, J. Chromatogr. A 1266 (2012) 158.

[15] I. François, P. Sandra, J. Chromatogr. A 1216 (2009) 4005.

[16] P.G. Stevenson, A. Tarafder, G. Guiochon, J. Chromatogr. A 1220 (2012) 175.

[17] J.M. Davis, D.R. Stoll, P.W. Carr, Anal. Chem. 80 (2008) 461.

[18] V. Abrahamsson, M. Sandahl, J. Chromatogr. A 1306 (2013) 80.

[19] J.N. Fairchild, J.F. Hill, P. Iraneta, LC-GC N. Am. 31 (2013) 326.

[20] A.P. Schellinger, D.R. Stoll, P.W. Carr, J. Chromatogr. A 1192 (2008) 41.

[21] A.P. Schellinger, D.R. Stoll, P.W. Carr, J. Chromatogr. A 1192 (2008) 54.

[22] C. Grivel, J.-L. Rocca, D. Guillarme, J.-L. Veuthey, S. Heinisch, J. Chromatogr. A 1217 (2010) 459.

[23] A. Grand-Guillaume Perrenoud, C. Hamman, M. Goel, J.-L. Veuthey, D. Guillarme, S. Fekete, J. Chromatogr. A 1314 (2013) 288. 
520 Figure 1 : RPLCxSFC setup. (a) The eluent of first dimension is stored in loop 1 while the content of loop 2 is injected in second dimension and (b) vice versa

Figure 2 : Influence of gradient profile on the dwell volume measurement in SFC. Mobile phases : $\mathrm{A}=\mathrm{CO}_{2}, \mathrm{~B}=\mathrm{MeOH}+0.1 \%$ acetone. Temperature $=30{ }^{\circ} \mathrm{C}$. $\mathrm{BPR}=140$ bar. Detection Wavelength $=254 \mathrm{~nm}$. Programmed gradient : (a) 1-99 \%B in $8 \mathrm{~min}$ at $1 \mathrm{~mL} / \mathrm{min}$, (b) $69-99 \% \mathrm{~B}$ in $3 \mathrm{~min}$ at $1.5 \mathrm{~mL} / \mathrm{min}$. Dotted lines are the tangents to the obtained gradient profile. $\Delta$ t represents the uncertainty at half part of the UV signal with $\mathrm{t}^{*}$ being the corresponding time.

Figure 3 : Observed inlet pressure of the SFC instrument vs run time in (a) 1D-SFC and (b) RPLC $\times$ SFC. Conditions common to all experiments : injection solvent = Water/ACN 95/5 (v/v); mobile phase $=$ CO2/MeOH/ACN 95/2.5/2.5 (v/v/v); column = Acquity UPC ${ }^{2} \mathrm{CSH}$ FP $50 \times 2.1 \mathrm{~mm}, 1.7 \mu \mathrm{m}$; temperature $=45^{\circ} \mathrm{C}$; BPR $=140$ bar. Other conditions : (a) flow rate $=2.7 \mathrm{~mL} / \mathrm{min}$, injected volume $=5 \mu \mathrm{L}$; (b) flow rate $=$ $2.0 \mathrm{~mL} / \mathrm{min}$, injected volume $=3 \mu \mathrm{L} . \Delta \mathrm{P}$ represents the pressure increase (see text for more details)

Figure 4 : Pressure increase $\Delta P$ in $1 D-S F C$ as a function of water content of the injection solvent and injection volume $V_{i}$ on (a) Acquity UPC ${ }^{2}$ CSH FP column, (b), Acquity UPC ${ }^{2}$ HSS C18 column, (c) Acquity UPC ${ }^{2}$ BEH column and (d) Acquity UPC ${ }^{2}$ BEH-2EP column. Column geometry : $50 \times 2.1 \mathrm{~mm}, 1.7 \mu \mathrm{m}$; flow rate $=2.7 \mathrm{~mL} / \mathrm{min}$; temperature $=45^{\circ} \mathrm{C} ; \mathrm{BPR}=140$ bar ; injection solvent $=$ mixture of water and acetonitrile. * means that $\Delta \mathrm{P}$ could not be measured because the pressure limit (414 bar) was reached.

Figure 5: Influence of ${ }^{2} \mathrm{D}$ stationary phase on the course of a RPLCxSFC experiment. (a) and (b) : SFC inlet pressure versus run time. c) and (d) : ${ }^{2} D$ analysis of fractions eluted from ${ }^{1} \mathrm{D}$ between 20.1 and $21.0 \mathrm{~min}$. (e) and (f) : ${ }^{2} \mathrm{D}$ analysis of fractions eluted from ${ }^{1} \mathrm{D}$ between 36.3 and $37.2 \mathrm{~min}$. Sampling time $=0.3 \mathrm{~min}$. RPLC conditions : column dimensions $=50 \times 1.0 \mathrm{~mm}$, stationary phase $=3.5 \mu \mathrm{m}$ Xbridge $\mathrm{C} 18$, solvent $\mathrm{A}$ $=$ water, solvent $B=A C N$, gradient from $1 \% B$ to $55 \% B$ in $29.3 \mathrm{~min}$, flow rate $=10$ $\mu \mathrm{L} / \mathrm{min}$, temperature $=30{ }^{\circ} \mathrm{C}$. SFC conditions : column dimensions $=50 \times 2.1 \mathrm{~mm}$, stationary phase $=(\mathrm{a}, \mathrm{c}, \mathrm{e}) 1.7 \mu \mathrm{m}$ Acquity UPC ${ }^{2} \mathrm{CSH} F \mathrm{~F} ;(\mathrm{b}, \mathrm{d}, \mathrm{f}) 1.7 \mu \mathrm{m}$ Acquity UPC ${ }^{2}$ $\mathrm{BEH}$, isocratic mobile phase $=\mathrm{CO}_{2} / \mathrm{MeOH} / \mathrm{ACN} 95 / 2.5 / 2.5(\mathrm{v} / \mathrm{v} / \mathrm{v})$, flow rate $=(\mathrm{a}, \mathrm{C}, \mathrm{e})$ $2.0 \mathrm{~mL} / \mathrm{min} ;(\mathrm{b}, \mathrm{d}, \mathrm{e}) 2.6 \mathrm{~mL} / \mathrm{min}$, temperature $=45^{\circ} \mathrm{C}, \mathrm{BPR}=140$ bar. Full lines shows 
552 the gradient profile in ${ }^{1} \mathrm{D}$ outlet. Dotted lines show the time windows for the selected 553 fractions.

554 Figure 6 : Effect of injection solvent and injected volume peak shape. Solute : o-cresol 555 with (a) $1 \mu \mathrm{L}$, (b) $5 \mu \mathrm{L}$, (c) $10 \mu \mathrm{L}$. Injection solvent composition: Water/ACN 95/5 (v/v) $556(-), 50 / 50(\mathrm{v} / \mathrm{v})(-)$ and $5 / 95(\mathrm{v} / \mathrm{v})(-)$. Column : Acquity UPC ${ }^{2}$ BEH-2EP, 50x2.1 $557 \mathrm{~mm}, 1.7 \mu \mathrm{m}$. Flow rate = $2.2 \mathrm{~mL} / \mathrm{min}$; mobile phase: $\mathrm{CO}_{2} / \mathrm{MeOH} / \mathrm{ACN}$ 95/2.5/2.5 (v/v/v). 558 Temperature $=45^{\circ} \mathrm{C}$. BPR $=140$ bar. Detection wavelength $=215 \mathrm{~nm}$ (compensation 559 from $350 \mathrm{~nm}$ to $450 \mathrm{~nm}$ ).

560 Figure 7 : schematic representation of injection process in the second dimension of 561 RPLCXSFC with (a) completely and (b) partially filling of the loops

562 Figure 8 : On-line RPLCXSFC separation of 12 aromatic compounds. (a) contour plot 563 UV and (b) overlay of SFC separation of the fractions from $27 \mathrm{~min}$ to $28.5 \mathrm{~min}$ (red 564 dotted lines in the contour plot). See Table 1 for solutes and Table 3 for experimental 565 conditions.

566 Figure 9 : Comparison (a) on-line RPLCxSFC and (b) on-line RPLCxRPLC separation 567 of a bio-oil aqueous extract. Experimental conditions are summarized in Table 3 . The red dotted lines in (b) delimit the separation space. 


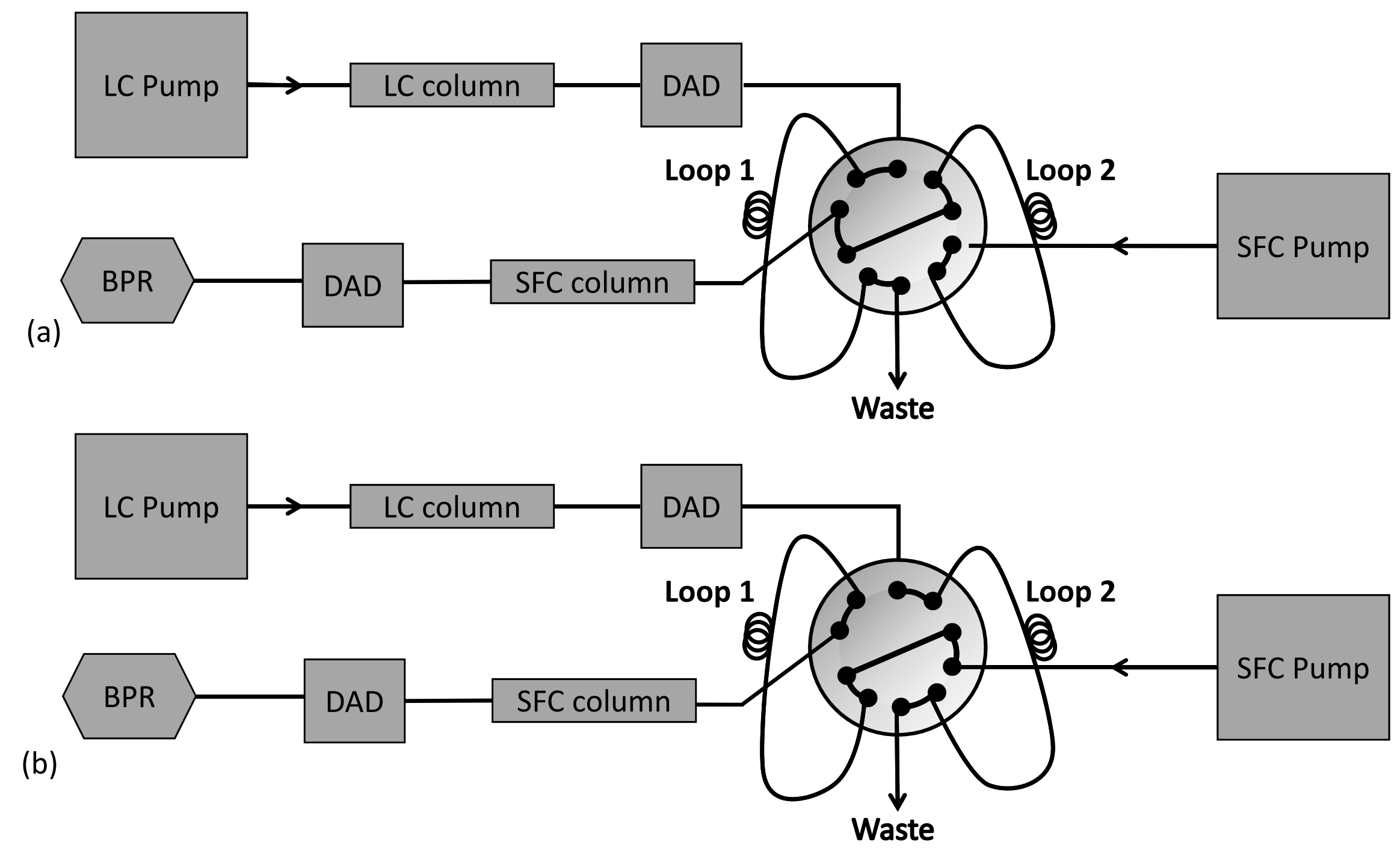

Figure 1 : 

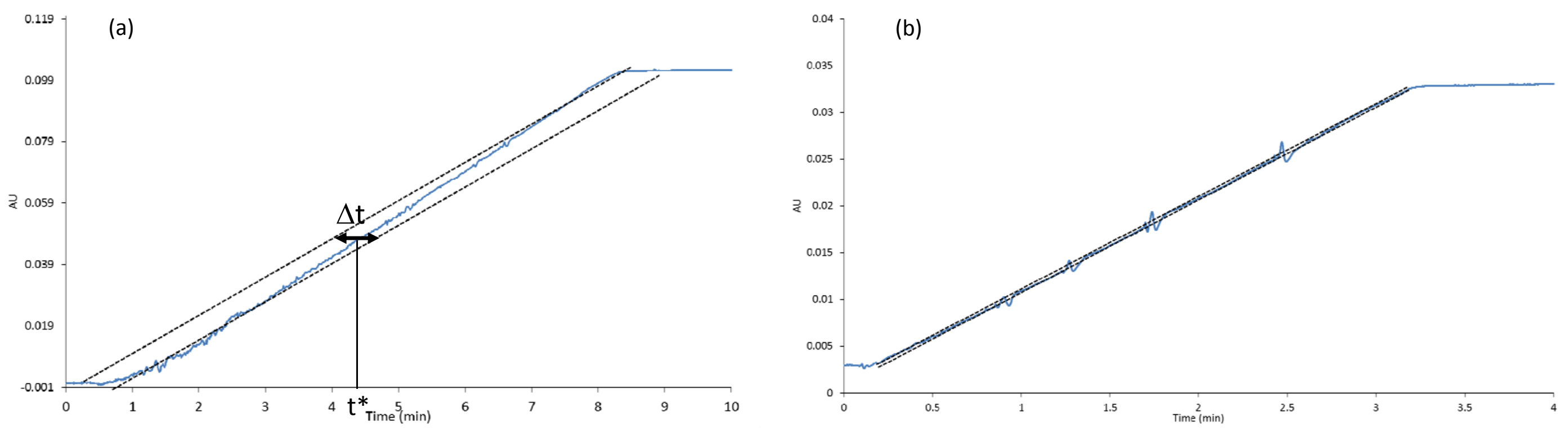

Figure 2 

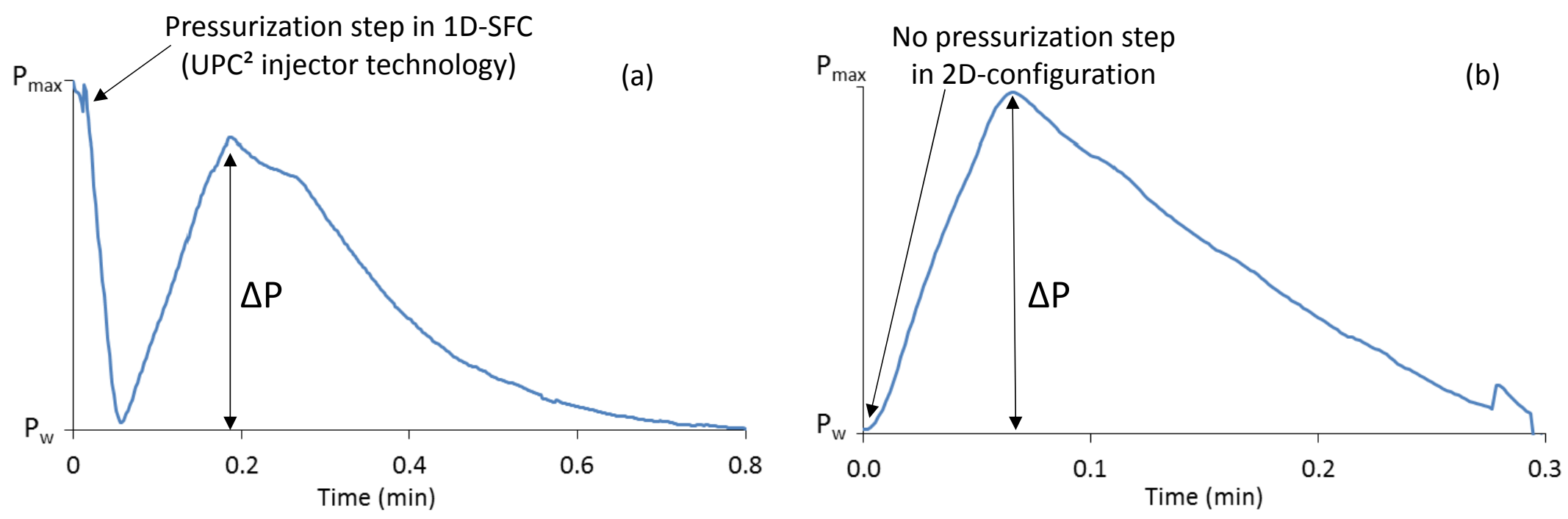

Figure 3 

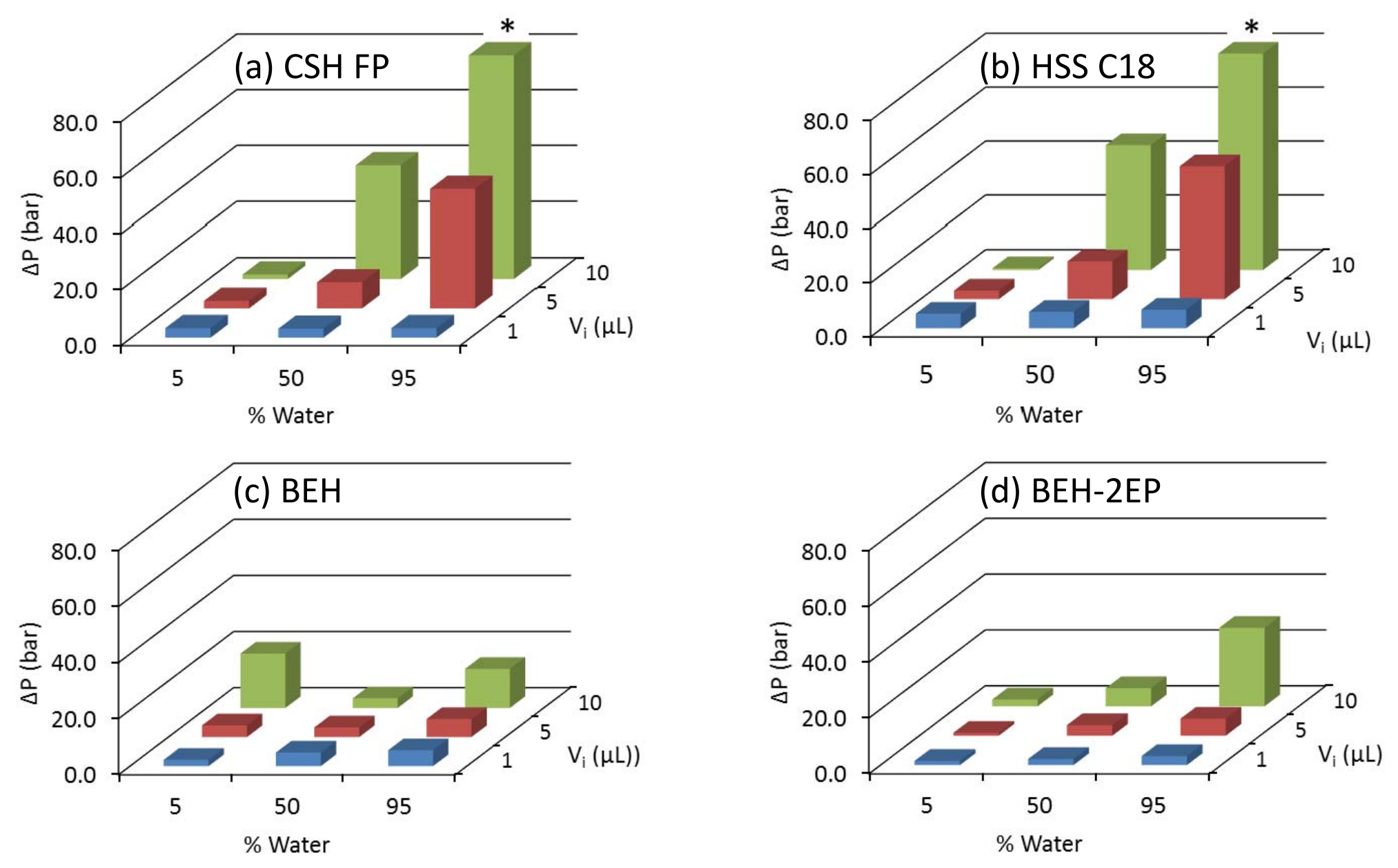

Figure 4 


\section{CSH FP column}
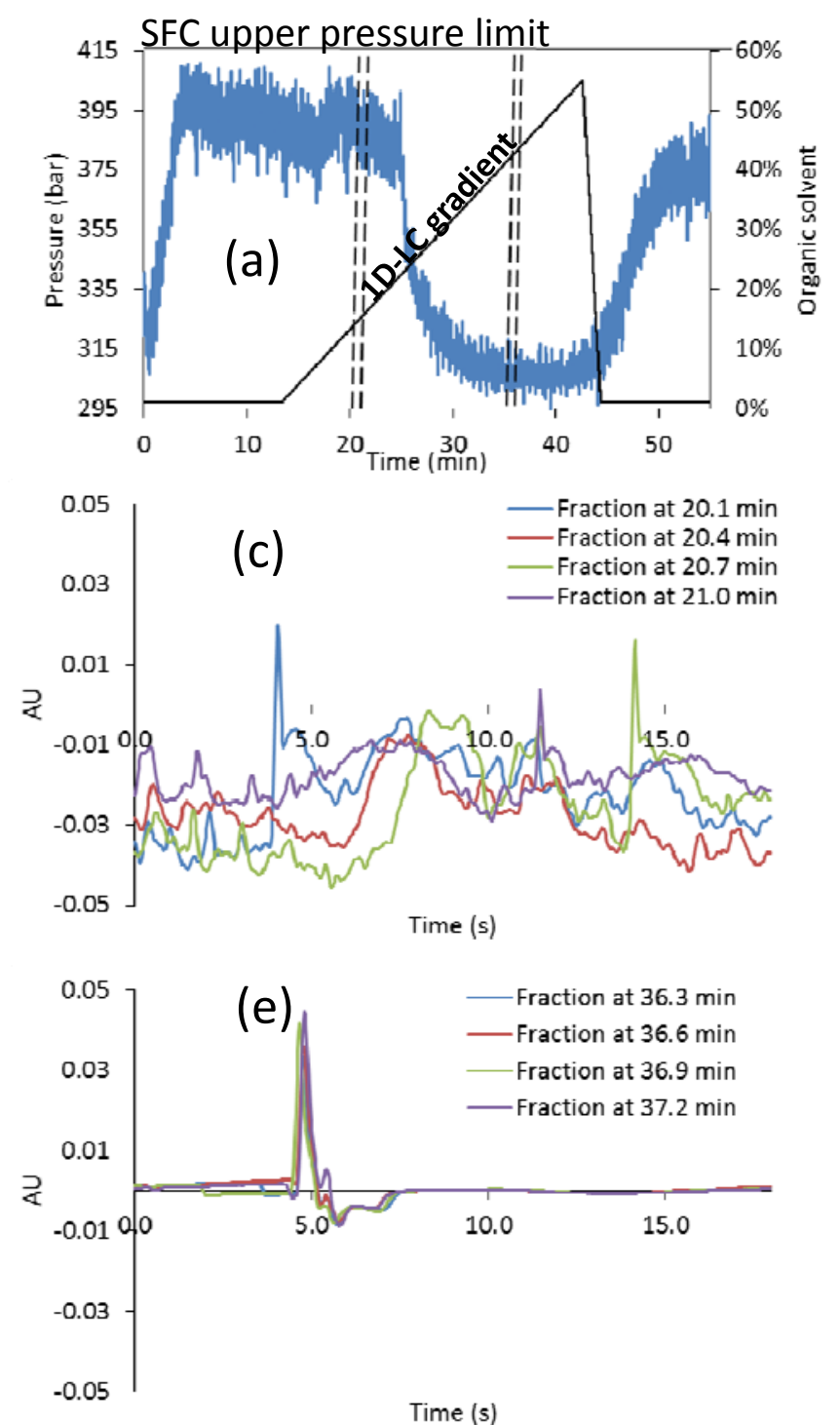

\section{BEH column}
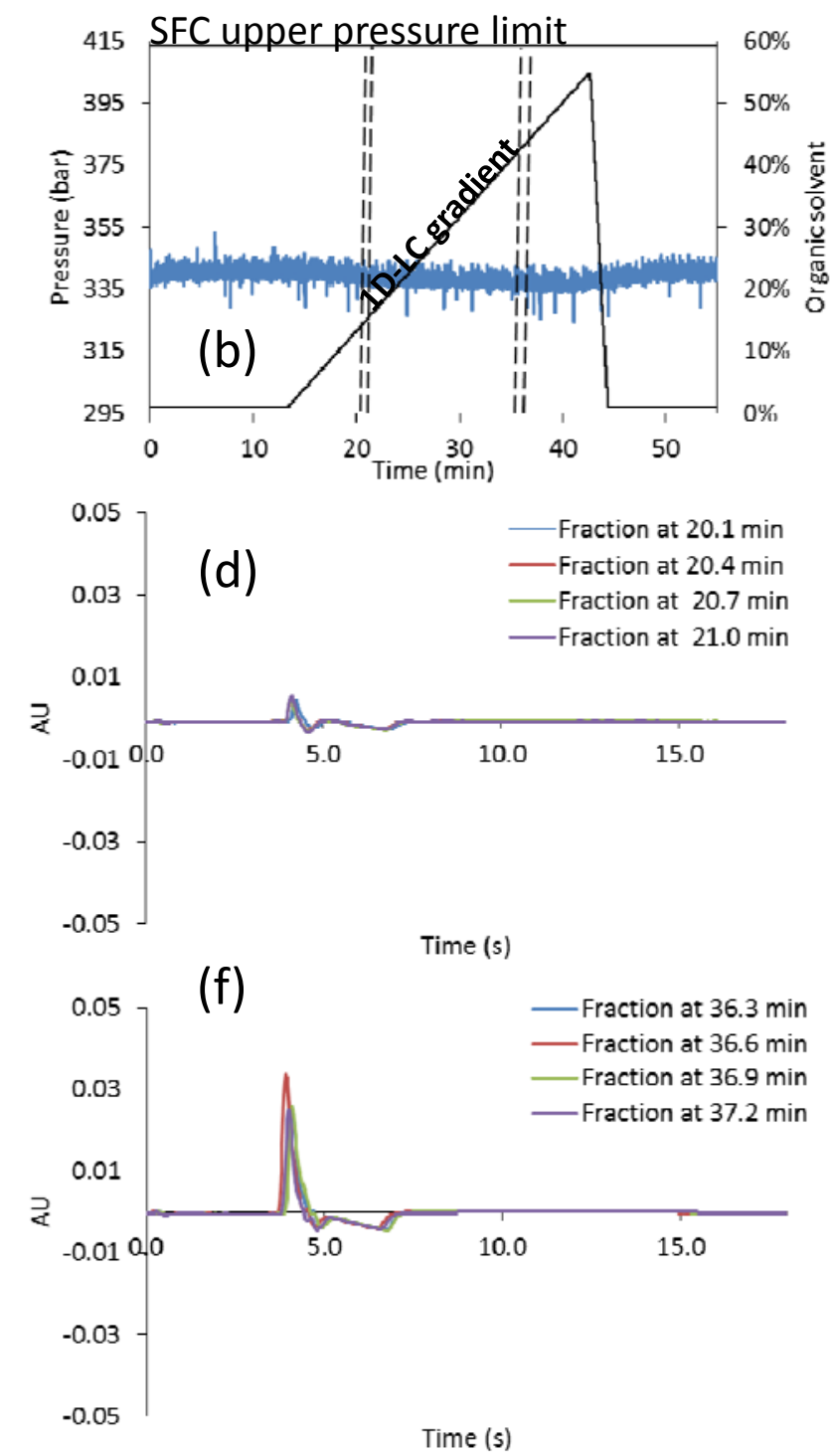

\section{Figure 5}



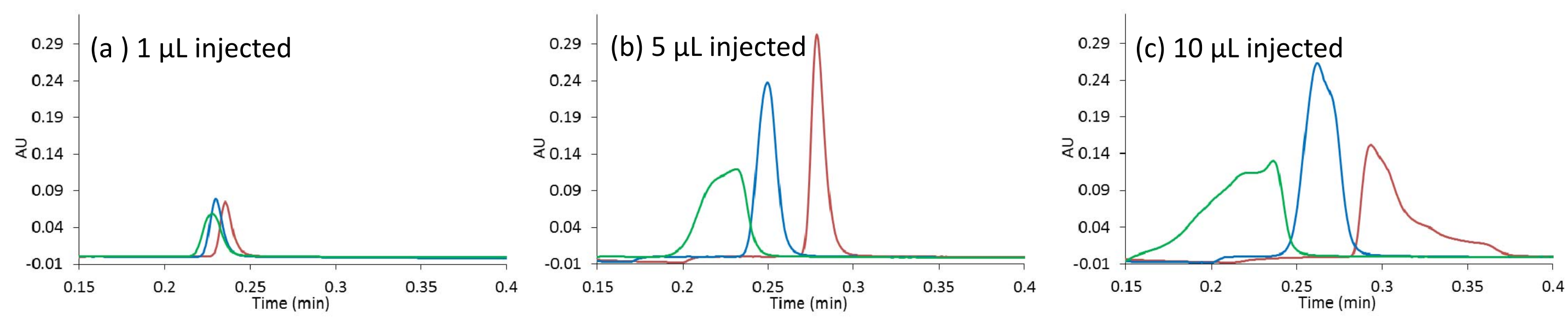

\section{Figure 6}


(a)

Identical volumes

\section{of loop and sample}

During the run (inject position)

\section{Loading}

(load position)

\section{End of Loading}

(load position)

Injection

(inject position)

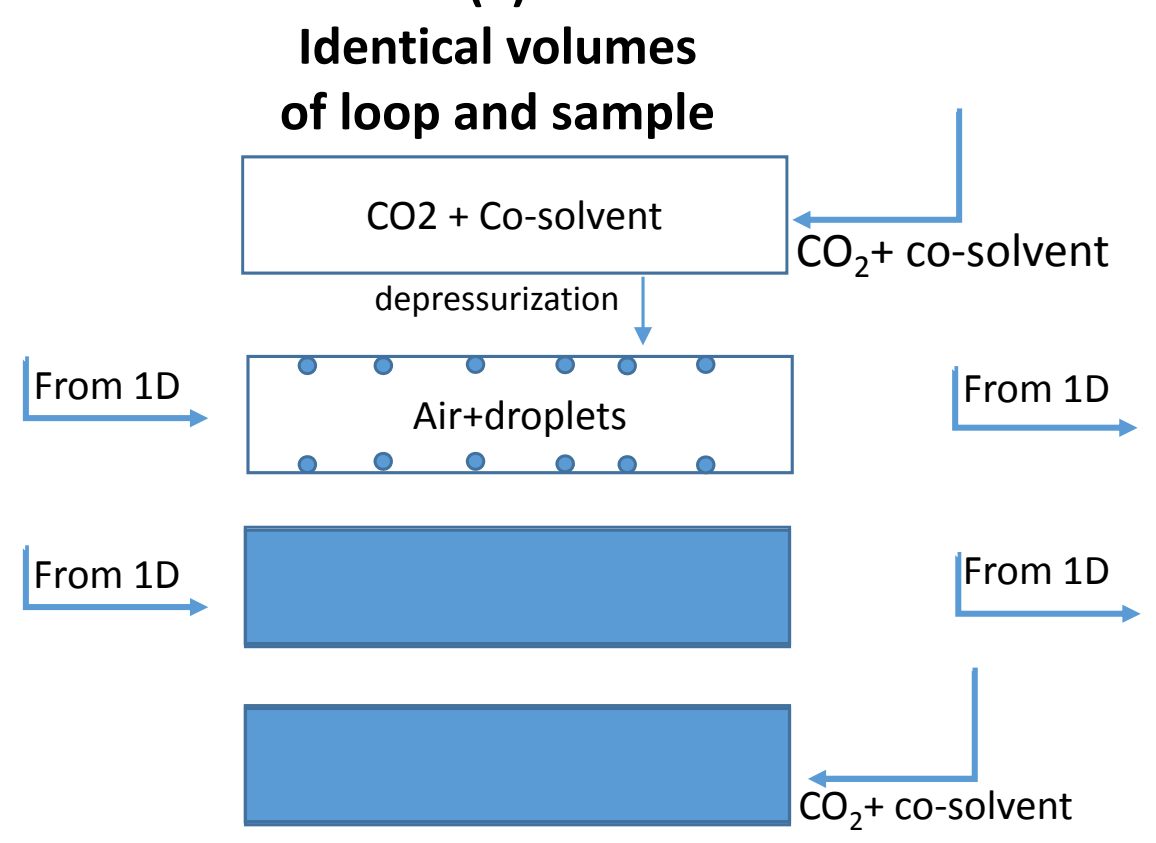

(b)

Larger volume of loop vs sample

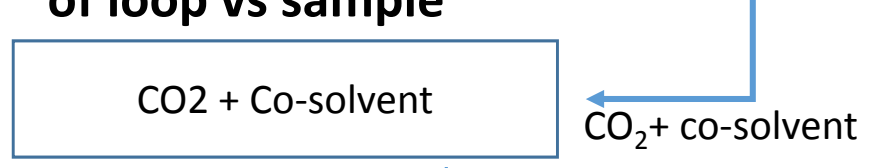

depressurization
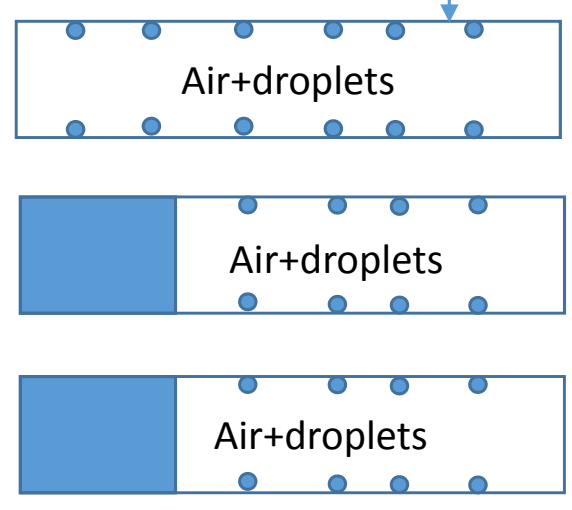

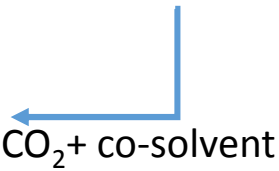

Figure 7 

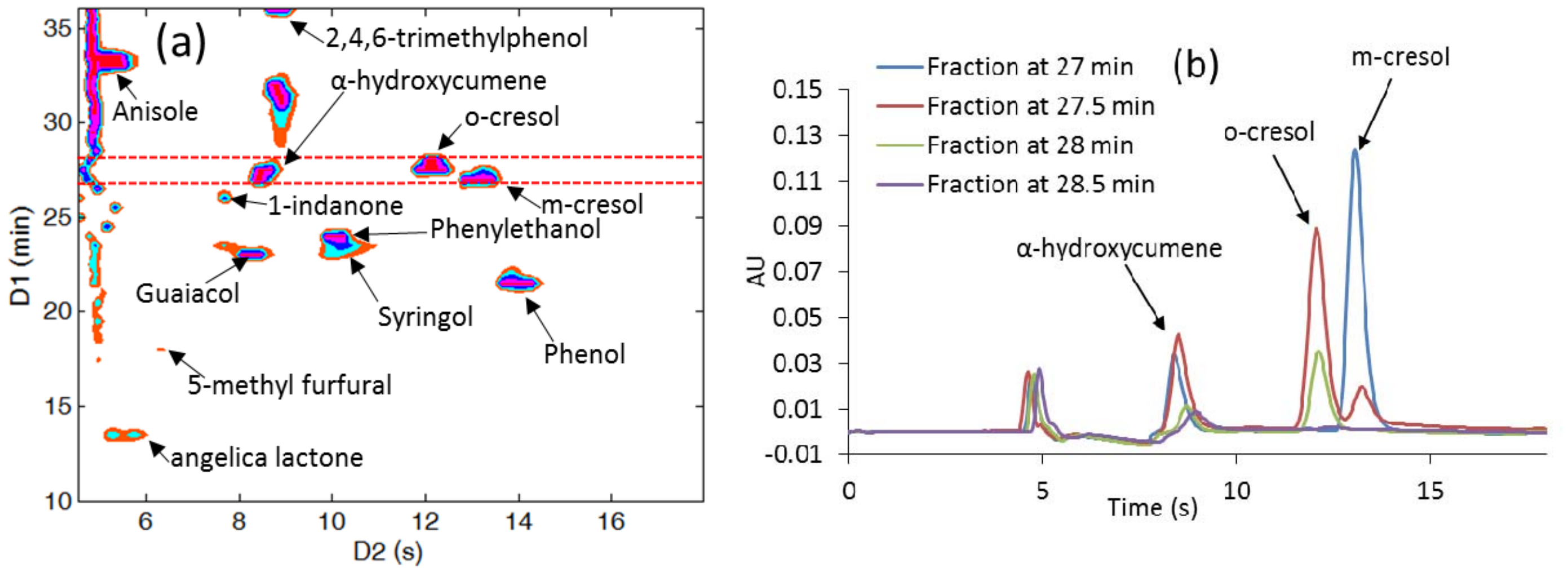

Figure 8 
(a) RPLCXSFC

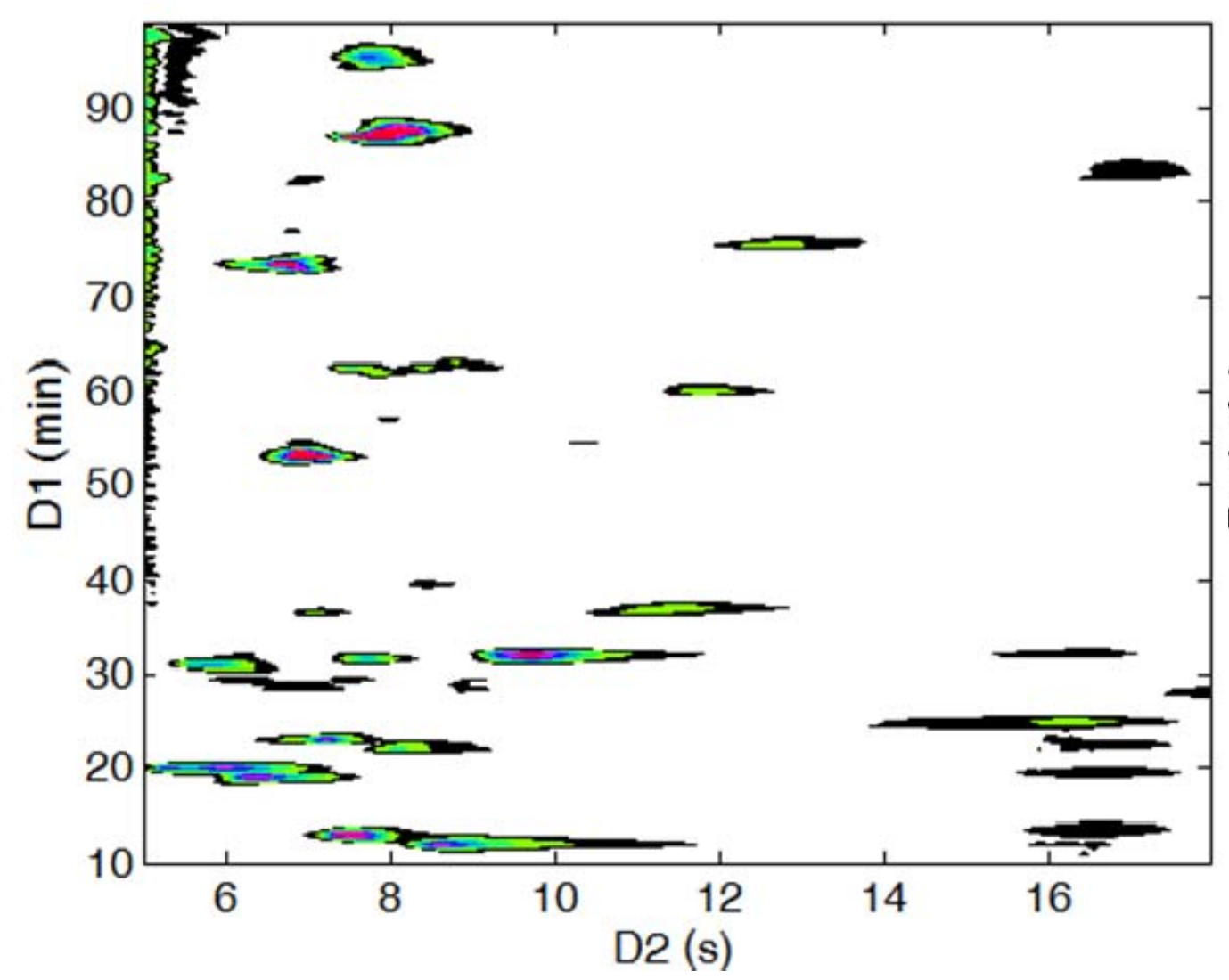

(b) RPLCXRPLC

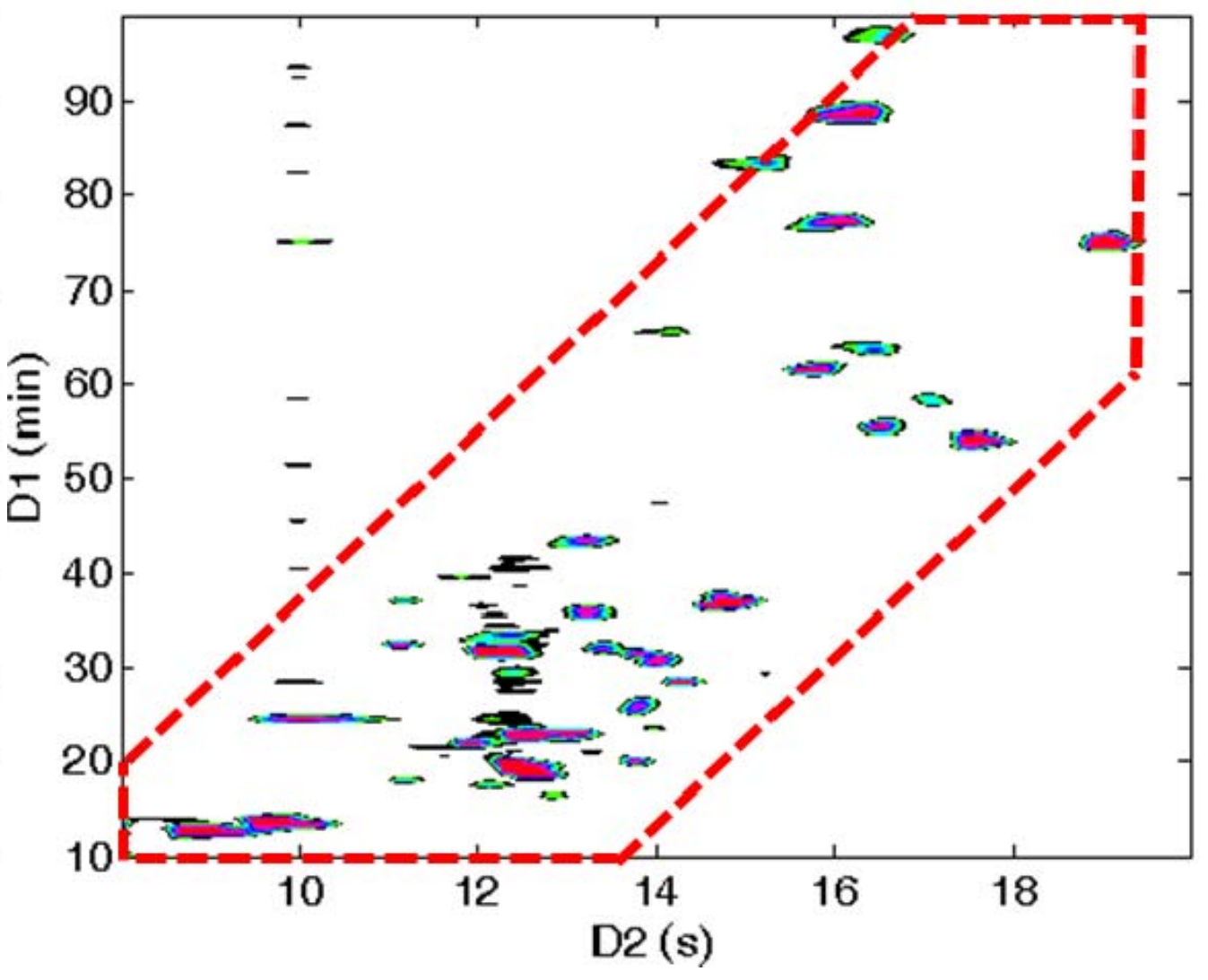

Figure 9 
1 Table 1 - Physical and chemical properties of some bio-oil representative compounds

\begin{tabular}{cccccc}
\hline & Compound & Chemical family & Molecular Formula & $\mathrm{MW}(\mathrm{g} / \mathrm{mol})$ & log $\mathrm{P}$ \\
\hline 1 & $\alpha$-angelica lactone & lactone & $\mathrm{C}_{5} \mathrm{H}_{6} \mathrm{O}_{2}$ & 98.10 & 0.236 \\
2 & 2-phenylethanol & alcohol & $\mathrm{C}_{8} \mathrm{H}_{10} \mathrm{O}$ & 122.16 & 1.504 \\
3 & 5-methylfurfural & furan & $\mathrm{C}_{6} \mathrm{H}_{6} \mathrm{O}_{2}$ & 110.11 & 0.670 \\
4 & phenol & phenol & $\mathrm{C}_{6} \mathrm{H}_{6} \mathrm{O}$ & 94.11 & 1.540 \\
5 & o-cresol & phenol & $\mathrm{C}_{7} \mathrm{H}_{8} \mathrm{O}$ & 108.14 & 1.962 \\
6 & m-cresol & phenol & $\mathrm{C}_{7} \mathrm{H}_{8} \mathrm{O}$ & 108.14 & 2.043 \\
7 & $2,4,6$-trimethylphenol & phenol & $\mathrm{C}_{9} \mathrm{H}_{12} \mathrm{O}$ & 136.19 & 2.935 \\
8 & $\alpha$-hydroxycumene & phenol & $\mathrm{C}_{9} \mathrm{H}_{12} \mathrm{O}$ & 136.19 & 2.861 \\
9 & guaiacol & guaiacol & $\mathrm{C}_{7} \mathrm{H}_{8} \mathrm{O}_{2}$ & 124.14 & 1.341 \\
10 & syringol & syringol & $\mathrm{C}_{8} \mathrm{H}_{10} \mathrm{O}_{3}$ & 154.16 & 1.218 \\
11 & 1-indanone & enone & $\mathrm{C}_{9} \mathrm{H}_{8} \mathrm{O}$ & 132.16 & 1.419 \\
12 & anisole & aromatic ether & $\mathrm{C}_{7} \mathrm{H}_{8} \mathrm{O}$ & 108.14 & 2.170
\end{tabular}


1 Table 3 - Experimental conditions for both RPLCXSFC and RPLCXRPLC separations

2 of the bio-oil aqueous sample

\begin{tabular}{cccc}
\hline & RPLC $\left({ }^{1} \mathrm{D}\right)$ & SFC $\left({ }^{2} \mathrm{D}\right)$ & RPLC $\left({ }^{2} \mathrm{D}\right)$ \\
\hline Stationary phase & Hypercarb & Acquity UPC ${ }^{2} \mathrm{BEH}-2 \mathrm{EP}$ & $\begin{array}{c}\text { Acquity CSH } \\
\text { Phenyl Hexyl }\end{array}$ \\
Column geometry & $100 \times 1.0 \mathrm{~mm}, 5 \mu \mathrm{m}$ & $50 \times 2.1 \mathrm{~mm}, 1.7 \mu \mathrm{m}$ & $50 \times 2.1 \mathrm{~mm}, 1.7 \mu \mathrm{m}$ \\
Mobile phase & $\mathrm{A}:$ Water & $\mathrm{A}: \mathrm{CO} 2$ & $\mathrm{~A}:$ Water $+0.1 \% \mathrm{FA}{ }^{*}$ \\
Flow rate & $\mathrm{B}: \mathrm{ACN}$ & $\mathrm{B}: \mathrm{MeOH} / \mathrm{ACN} 1: 1(\mathrm{v} / \mathrm{v})$ & $\mathrm{B}: \mathrm{ACN}+0.1 \% \mathrm{FA}$ \\
Gradient & $10 \mu \mathrm{L} / \mathrm{min}$ & $2 \mathrm{~mL} / \mathrm{min}$ & $1.2 \mathrm{~mL} / \mathrm{min}$ \\
BPR & 5 to $99 \%(\mathrm{~B})$ in $102.5 \mathrm{~min}$ & 15 to $50 \%(\mathrm{~B})$ in $0.12 \mathrm{~min}$ & 5 to $55 \%(\mathrm{~B})$ in $0.18 \mathrm{~min}$ \\
Temperature & $/$ & $140 \mathrm{bar}$ & $/$ \\
UV & $30^{\circ} \mathrm{C}$ & $45^{\circ} \mathrm{C}$ & $80^{\circ} \mathrm{C}$ \\
& & $220 \mathrm{~nm}$ & $220 \mathrm{~nm}$ \\
Injected volume & $220 \mathrm{~nm}$ & Compensation from 350 to & $450 \mathrm{~nm}$ \\
\hline
\end{tabular}

$30.5 \mathrm{~min}$ as sampling time

4 * FA means formic acid 
1 Table 2 - Experimental conditions for the RPLCXSFC separation of the 12 2 representative compounds (see list in table 1)

\begin{tabular}{ccc}
\hline & $\mathrm{RPLC}\left({ }^{1} \mathrm{D}\right)$ & $\mathrm{SFC}\left({ }^{2} \mathrm{D}\right)$ \\
\hline Stationary phase & $\mathrm{X}$ Bridge BEH C18 & Acquity UPC ${ }^{2} \mathrm{BEH}-2 \mathrm{EP}$ \\
Column geometry & $50 \times 1.0 \mathrm{~mm}, 3.5 \mu \mathrm{m}$ & $50 \times 2.1 \mathrm{~mm}, 1.7 \mu \mathrm{m}$ \\
Mobile phase & $\mathrm{A}:$ Water & $\mathrm{A}: \mathrm{CO} 2$ \\
Flow rate & $\mathrm{B}: \mathrm{ACN}$ & $\mathrm{B}: \mathrm{MeOH} / \mathrm{ACN} 1: 1(\mathrm{v} / \mathrm{v})$ \\
Gradient & $10 \mu \mathrm{L} / \mathrm{min}$ & $2 \mathrm{~mL} / \mathrm{min}$ \\
BPR & 8 to $51 \%(\mathrm{~B})$ in $23 \mathrm{~min}$ & Isocratic $5 \%$ (B) \\
Temperature & $/$ & $140 \mathrm{bar}$ \\
UV & $30^{\circ} \mathrm{C}$ & $45^{\circ} \mathrm{C}$ \\
Vinj & $220 \mathrm{~nm}$ & $215 \mathrm{~nm}$ \\
\hline
\end{tabular}

30.5 min as sampling time 
1 Table 4 - Experimental results of RPLCxSFC and RPLCxRPLC

\begin{tabular}{|c|c|c|c|c|c|c|c|}
\hline & $\gamma$ & $\alpha$ & ${ }^{1} \mathrm{n}$ & ${ }^{2} W_{4 \sigma}(s)$ & ${ }^{2} \mathrm{n}$ & ${ }^{1} n \cdot{ }^{2} n$ & $\mathrm{n}_{2 \mathrm{D}, \text { effective }}$ \\
\hline RPLCxSFC & 1 & 0.85 & 56 & 1.09 & 13 & 730 & 620 \\
\hline RPLCxRPLC & 0.59 & 0.85 & 56 & 0.60 & 20 & 1120 & 560 \\
\hline \multicolumn{8}{|l|}{2} \\
\hline \multicolumn{8}{|c|}{ were calcuta } \\
\hline \multicolumn{8}{|c|}{$4 \quad \gamma$ was calculated according $[6]$} \\
\hline \multicolumn{8}{|l|}{5} \\
\hline $6 \quad \mathrm{n}_{2 \mathrm{D} \text {,effecti }}$ & s calcul & ording & & & & & \\
\hline
\end{tabular}

